This is your page to write to and open up topics for debate, reply to each other and offer advice. One letter we have for this issue calls for more therapists to be trained instead of more dentists. What are your thoughts and contributions? Letters can be about your profession only or about working in dentistry in general.

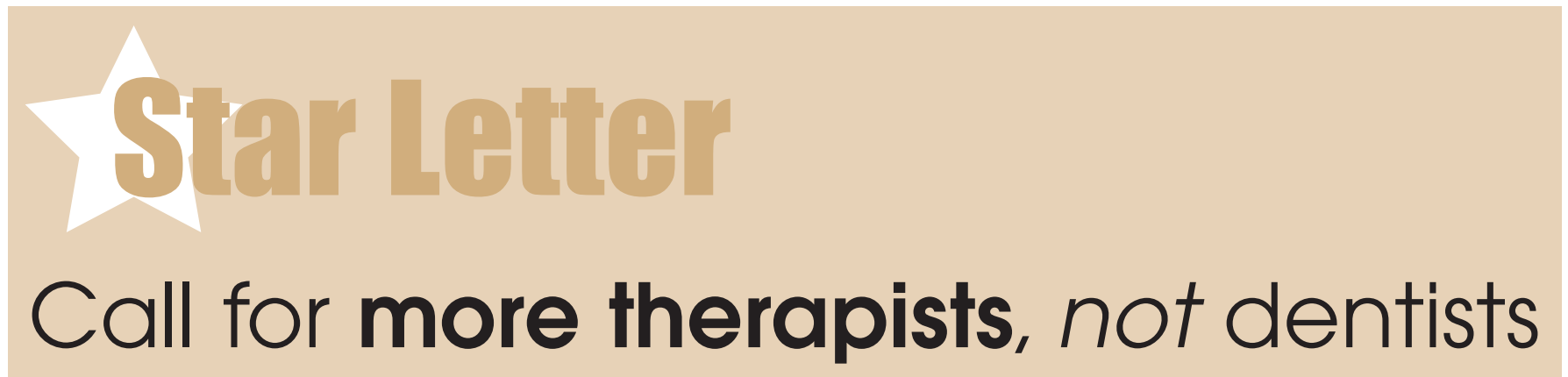

I read with dismay the recent announcements by Minister for Health Dr John Reid concerning the plans to resuscitate NHS Dental Care. The present Government are hell bent on a package that will do nothing for the basic ailments that bedevil the attempts to deliver decent oral healthcare to the population.

1. Patients - by stealth and ever increasing charges over the years - fund the greater part of treatment at point of use. This amounts to a massive injection of capital and is an outrageous imposition in a National Health Service purported to deliver the health needs of the population without charge when required. Why is it that the mouth and oral healthcare are some totally different deal? Imagine what would happen if in a comparable situation some little old lady was asked to pay $\mathfrak{£ 3 7 0 . 0 0}$ or so towards a necessary hip replacement procedure! Every tabloid and media outlet would be screaming in a millisecond. Whilst no one protests this will of course continue despite it being so hugely illogical.

2. Dr Reid tells us that "The equivalent (sic) of 1,000 dentists will be recruited by October 2005" Why? It seems that many from outside the UK will be fast tracked in the desperation to fill manpower needs whilst standards slide even further. What is the justification for this influx of dental professionals?

3. Dr Reid delivers a pledge to fund 170 extra undergraduate training places from October 2005. Why? What we really need are dental therapists and hygienists. Dentists are largely over trained to deal with the large amounts of the relatively simple treatment procedures that are needed to stabilise oral health in the population. Advanced restorative procedures will be in the minority. Dental therapists can be trained in 27 months to do much of the restorative dentistry needed and hygienists in even less time to deal with the important basic periodontics.

What then as an alternative to the above, do the people of the UK deserve?

1. Remove NHS charges, put the mouth back in the body and properly re-integrate dental care into the rest of the NHS.

2. Salaries for all NHS dentists and a fair rent from the DoH to practice principals for existing and already capitalised practice premises.

3. Practice teams (the 'professions complimentary to dentistry') to have direct salaried contracts with the DoH. Registration, accredited training, and continuing professional development programmes to be mandatory to enable this.

4. Train more therapists and hygienists (especially therapists) not dentists.

5. Revise the availabilty of 'luxury items' within NHS regulations.

John Reid said "Dental services will be properly integrated with the rest of the NHS providing better access to services and an improved patient experience." How, is this to happen under such a programme?

Yours faithfully

Dr K. F. Marshall, Specialist in Restorative Dentistry, Surrey

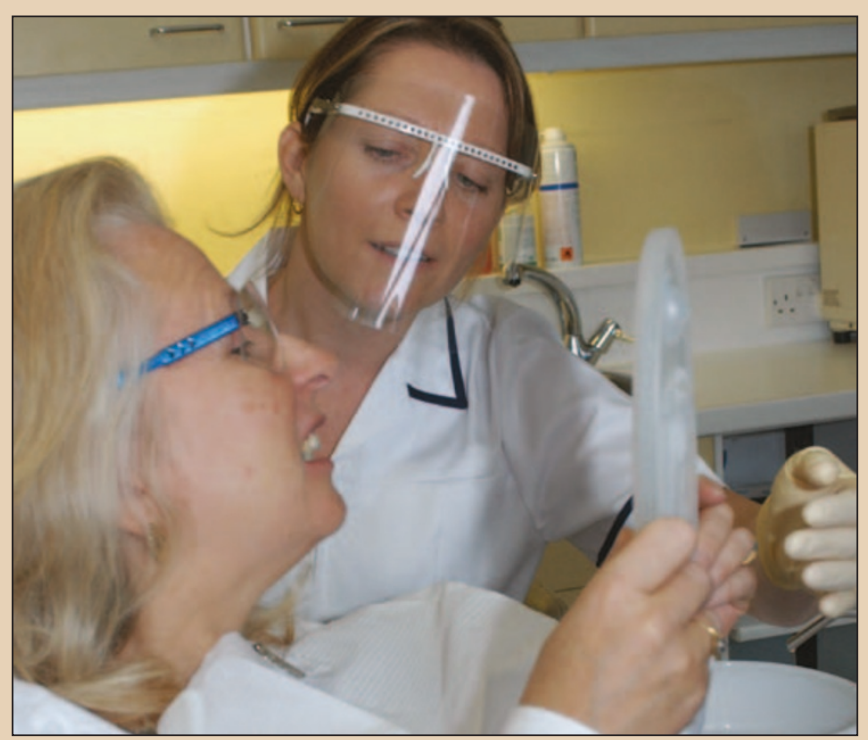

Dr Marshall calls for more therapists and hygienists, not dentists 


\section{Support for the NVQ}

I have just read the star letter in regards to Dental Nurses and the NVQ. This is a great opportunity for dental nurses to have a recognised qualification and not just treated as assistant to the dentist. I am fed up to the back teeth (excuse the pun) of being called this after all a dentist could not survive without us!

I have been a dental nurse for 6 years now and am now training for my Al award in assessing and cannot wait to get out there and help guide candidates in the right way of dental nursing.
Yes it is going to take time to get this NVQ off the ground but we must keep pushing for it as it is defiantly the right path for dental nursing to take.

\section{Mrs Jane Beauchamp,}

Dental Nurse

\section{Vital responds:}

Many thanks to Jane for her letter, she will be interested in the article on becoming an NVQ assessor on page 24.

SEND YOUR LETTERS to: the Editor, Vital Magazine, BDJ, Nature Publishing Group, 4-6 Crinan Street, London NI 9XW or email vitaleditorial@nature.com. Authors must sign the letter, which may be edited for reasons of space.

Our star letter writer will receive a Sonnet Black Laque fountain pen (£90 RRP) courtesy of Parker Pens.

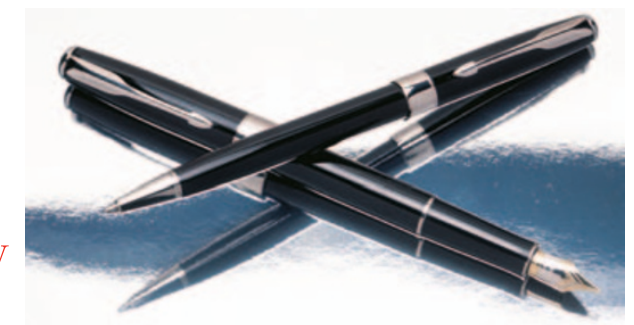

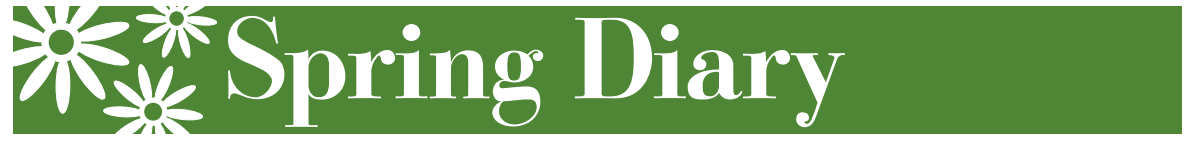

London BADT Regional Meeting

Date: $\quad 16.04 .05$

Venue: Q Clinic in Harley Street, London

Contact: 01189479399

Website: www.badt.org.uk

BADT and BDHA South Wales and South West Regional Study Day

Date: $\quad 23.04 .05$

Venue: The Castle Hotel, Castle Green, Taunton, Somerset

Contact: Jane Lewis - 01189482651

Website: www.badt.org.uk

Dental Sedation Teachers' Group Annual Symposium 2005

Date: $\quad 26.04 .05$

Venue: The Royal College of Physicians and Surgeons of Glasgow

Contact: 01412216072

Website: www.dstg.co.uk
BADN 2005 Annual Dental

Nursing Conference

Date: 29.04.05-01.05.05

Venue: Gatwick Renaissance Hotel

Contact: 01253338360

Website: www.badn.org.uk

British Dental Association Conference and Exhibition 2005

Date: 19-21.05.05

Venue: Scottish Exhibition and Conference Centre (SECC), Glasgow

Contact: 02075634590

Website: www.bda-events.org

$\begin{array}{ll}\text { PCD Roadshows } \\ \text { Date: } & 22 \text { March } 2005 \\ \text { Venue: } & \text { Everglades Hotel, Derry } \\ \text { Date: } & 23 \text { March } 2005 \\ \text { Venue: } & \text { Europa Hotel, Belfast }\end{array}$

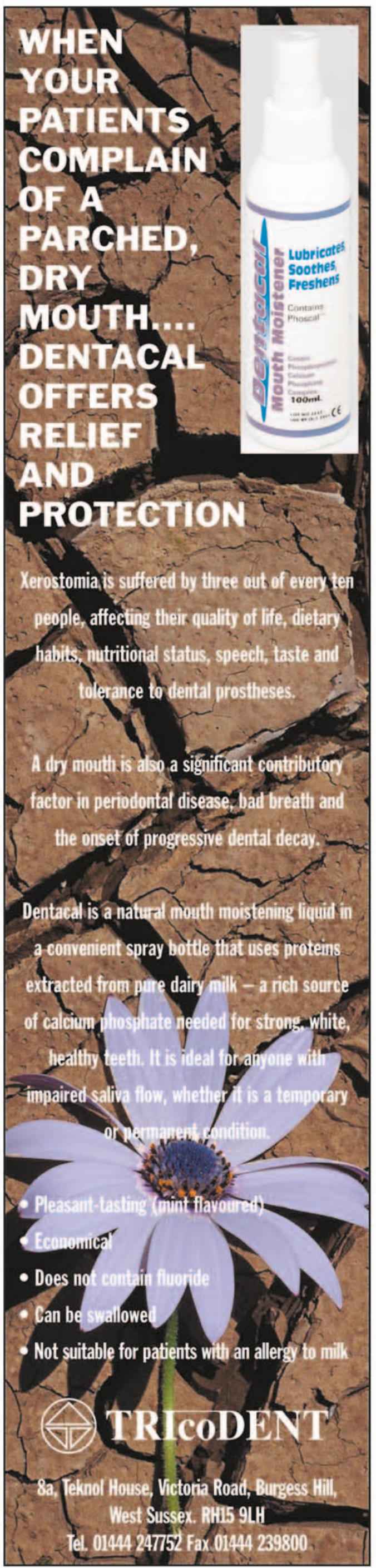

